\title{
BMJ Open Perceptions of parents and paediatricians on pain induced by bone marrow aspiration and lumbar puncture among children with acute leukaemia: a qualitative study in China
}

Yu Wang, ${ }^{1}$ Qiang Liu, ${ }^{1}$ Jia-Ning Yu, ${ }^{2}$ Hai-Xia Wang, ${ }^{3}$ Lu-Lu Gao, ${ }^{1}$ Ya-Liang Dai, ${ }^{1}$ Xin Jin, ${ }^{4}$ Feng Zuo, ${ }^{2}$ Juan Liu, ${ }^{1}$ Cai-Feng Bai, ${ }^{1}$ Guo-Xia Mu, ${ }^{1}$ Xiao-Min Chai, ${ }^{1}$ Yin-Juan Zhang, ${ }^{1}$ Yu-Xiang Li, ${ }^{1}$ Jian-Qiang $\mathrm{Yu}^{5}$

To cite: Wang Y, Liu Q, Yu J-N, et al. Perceptions of parents and paediatricians on pain induced by bone marrow aspiration and lumbar puncture among children with acute leukaemia: a qualitative study in China. BMJ Open 2017;7:e015727. doi:10.1136/ bmjopen-2016-015727

- Prepublication history for this paper is available online. To view these files please visit the journal online (http://dx.doi. org/10.1136/bmjopen-2016015727).

YW, QL, J-NY and H-XW contributed equally.

Received 27 December 2016 Revised 28 July 2017 Accepted 8 August 2017

CrossMark

For numbered affiliations see end of article.

Correspondence to

Dr Yu-Xiang Li;

li_yuxiang@163.com and Jian-

Qiang Yu;

yjq910315@163.com

\section{ABSTRACT}

Objective To obtain in-depth insight into the perceptions of parents and paediatricians in China regarding current procedural pain management on bone marrow aspirations and lumbar punctures in paediatric haemato-oncology department.

Design, setting and participants This qualitative study was conducted in a 4500-bed university hospital in northwest China. To collect data, in-depth semistructured interviews were conducted with parents of children with acute leukaemia $(n=12)$ and haemato-oncology paediatricians $(n=11)$ using purposive sampling. Interviews were audiotaped and transcribed and subjected to thematic analysis.

Results The suffering of procedural pain among paediatric patients was not adequately recognised and properly treated at the paediatric haemato-oncology department. The current paediatric procedural pain management is inadequate for paediatric patients. Crucial factors were identified including lack of awareness about the damage of uncontrolled pain in children, parents' low supportive ability, the limited capacity to provide general analgesia by anaesthetists, inadequate knowledge in the usage of analgesia and sedation and lack of efficient analgesic for children's procedural pain. The participants strongly expected optimal interventions to improve paediatric procedural pain management.

Conclusions The result suggested a perceived and actual poor management of paediatric procedural pain in haemato-oncology department in northwest China. A relevant pain management education programme for paediatricians and parents as well as an effective pain medication are urgently needed in northwest China. Trial registration Chinese Clinical Trial Registry. Identifier: ChiCTR-INR-16007989.

\section{INTRODUCTION}

Childhood acute leukaemia (AL), the most common childhood malignancy, is the successful sign of medical research. The 5-year survival rate of childhood $\mathrm{AL}$ is $84 \%$ in the
Strengths and limitations of this study

- This is the first study to use a qualitative method to focus on the parents' and paediatricians' voices regarding paediatric procedural pain management in an underdeveloped area.

- Conducting semistructured interviews with parents of children with acute leukaemia and haematooncology paediatricians enabled researchers to gain a comprehensive understanding of the barriers that paediatric procedural pain management faces in the current research hospital.

- Our participants represented the population in a remote part of China; therefore, our findings may not reflect the situation of China comprehensively.

USA and $70.5 \%$ in China. ${ }^{12}$ Nevertheless, the treatment is arduous. Treatment for paediatric AL at our institution requires an average of 12 bone marrow aspirations (BMAs) and 15-30 lumbar punctures (LPs) for intrathecal chemotherapy depending on acute lymphoblastic leukaemia (ALL) risk category. LPs and BMAs play central roles in the diagnosis and treatment and are associated with high levels of anxiety and pain. These repeated invasive procedures are considered to be the most traumatic episodes by paediatric patients with haematological diseases. ${ }^{3}$ Additionally, these repeated invasive procedures are emotionally stressful events for parents of a child with leukaemia. ${ }^{4}$

Since the 1980s, unrelieved paediatric pain has been reported with negative physiological, psychological and emotional consequences. ${ }^{56}$ The second International Association for the Study of Pain Global Day Against Pain focused on children's pain and called for pain treatment improvement in 
this vulnerable segment of the population. ${ }^{7}$ Additionally, performing LPs and BMAs without optimal interventions to minimise anxiety and pain among children, their incooperation and movement can increase the risk of failures, postdural puncture headaches and samples being haemorrhagic. $^{8-10}$ Low puncture success rates will, in turn, aggravate anxiety.

Pharmacological and non-pharmacological treatments to control procedural pain have been well studied in paediatric haematological patients. ${ }^{1-17}$ In particular, the recommendations and guidelines of pharmacological and non-pharmacological practice to improve the quality of LPs and BMAs procedure-related pain management have been developed by numerous national organisations. ${ }^{18-20}$ However, the awareness of evidence-based paediatric pain management during invasive procedures in China remains a major concern. There is no specific reference standard for paediatric LPs and BMAs procedural pain management.

The present study aimed to conduct a qualitative research base by interviewing parents and paediatricians and exploring their perceptions in relation to pain management of LPs and BMAs for childhood AL. From this study, the factors leading to poorly controlled paediatric procedural pain may be exposed, and the high priority and evidence-based design of paediatric procedural pain relief programme would be developed for clinical practice accordingly.

\section{METHODS \\ Design}

Our work focused on perceptions of parents and paediatricians about LPs and BMAs procedural pain management, so we chose a qualitative approach. Descriptive phenomenology was the methodological basis for this qualitative study, which focused on comprehensively summarising targeted events, experience or perceptions through 'low-inference' interpretation. ${ }^{21}$ These qualitative, semistructured interviews were conducted in the northwest of mainland China at a 4500-bed university hospital, which was the only one providing paediatric AL treatment in the region.

\section{Ethical consideration}

This study was a part of a larger study that has been evaluated and approved by the General Hospital of Ningxia Medical University Ethics Service Committee (2015-130). Parents and paediatricians were given verbal and written information about the aims and procedures of this qualitative study, the right to withdraw at any time, the usage of tape-recording and the promise of confidentiality by the researchers. Consent forms were signed by all participants before the interview.

\section{Sampling and recruitment}

Recruitment for this qualitative study took place between 1 November 2015 and 31 April 2016. We used purposive sampling $^{22}$ to recruit participants to achieve a representative distribution of the factors that we wanted to study, such as clinical experience and education level. Parental inclusion criteria were: (1) children were diagnosed with AL and undergoing LPs and BMAs irrespective of treatment phase and disease duration; and (2) sufficient fluency in Mandarin Chinese as judged by the interviewer. This was to ensure free expression of their experiences because all interviews were conducted in Mandarin Chinese. Paediatricians were eligible if they had more than 3 months' working experience in the paediatric onco-haematological unit.

\section{Data collection}

Via preliminary visits to the paediatric onco-haematological unit, we became familiar with the families and paediatricians before the first data collection dialogue took place. The interviews were semistructured according to an interview guide that had been developed based on the research question, existing literature and discussion within the study team. The choice to use semistructured interviews was made on the basis that it would allow superior handling and analysis of the information, which also helped in improving the quality of data, because the interviewers were able to make sure that the participants would be understood. The face-to-face interviews were carried out by YW, a master candidate trained in nursing science. All interviews took place in the meeting room of the paediatric onco-haematological unit. Only the interviewer and interviewee were present throughout the interview proceeding so as to eliminate the concerns of the participants. Date and time were mutually agreed on. Interviews, conducted in Chinese, were approximately $30-60 \mathrm{~min}$ in length. All of the interviews were audiotaped. In addition, participants' responses to the interview questions and their performance of the process of answering questions were recorded for subsequent analysis. Questioning techniques, such as using silence and probing questions, were also adopted to find out more details during each interview. The interviewing techniques of YW were judged appropriate by the interviewing expert (Y-XL).

Many of the questions were used in a previous study ${ }^{23}$ that investigated the perceptions of cancer pain management of family caregivers, patients and acquaintances and health professionals (nurses and physicians) in northwest China. These questions were adapted to parents of a child with AL and paediatricians working in haemato-oncology units.

The primary question for the paediatricians was: 'What is your opinion about pain management of the repeated BMAs and LPs in the Paediatric Hemato-Oncology department?' Other questions inquired about clinical use of sedation and analgesia for these invasive procedures and clinical reason or criteria as well as their expectations for ideal paediatric procedural pain management. The leading question for parents was: 'What is the performance of your children undergoing BMAs and LPs?' 
Some of the probe questions were regarding their feelings and perceptions of the current BMAs and LPs procedural pain management and their expectations.

\section{Data analysis}

The data were collected and analysed iteratively. ${ }^{24}$ Audiotapes were transcribed verbatim into Chinese by the authors (L-LG, Y-LD, XJ and G-XM). Three researchers were involved in the process of data analysis ( $\mathrm{YW}, \mathrm{QL}$ and H-XW) using a thematic analysis. ${ }^{25}$ Thematic analysis, a method for identifying, analysing and reporting themes within data, should be seen as a foundational method for qualitative analysis. ${ }^{26}$ Through its theoretical freedom, thematic analysis provides a flexible and useful research tool, which can potentially provide a rich and detailed yet complex account of data. As thematic analysis does not require the detailed theoretical and technological knowledge of approaches, it can offer a more accessible form of analysis, particularly for those early in a qualitative research career. These three researchers read and reread the transcripts of the interviews, coded the first five transcripts independently and grouped them into themes. X-MC and JL were subsequently invited to review these codes and themes. Audio recordings were also used to check the transcripts and codes. Then these independent coding and themes were discussed by the research team, and a coding framework was developed and applied to all transcripts. In this inductive and iterative process, new themes emerged that were discussed and adapted. Constant comparison was also used to refine these synthesised themes. Having interviewed 12 parents and 11 paediatricians, the data reached the point of no new coding, no new themes and no new data and were therefore saturated. ${ }^{27}{ }^{28}$ Because of the intention to have ample description and to target English-language journals, the results were translated into English by two translators outside the research team.

\section{RESULTS}

The suffering of procedural pain among paediatric patients was not adequately recognised and properly treated at our paediatric haemato-oncology department. Three superordinate themes emerged through analysis of the data. These themes and associated subordinate themes are summarised in figure 1. These aforementioned themes are described in more detail below, along with verbatim quotes to exemplify the interpretative process. Pseudonyms have been used throughout. While analysis was conducted separately for parents and paediatricians, the results were similar, and the findings were presented jointly.

\section{The inadequate state of current paediatric procedural pain management \\ Physical restraint and no local anaesthetic}

Although lidocaine infiltration around the puncture site is the standard clinical practice for BMAs and LPs, all residents in paediatric conveyed that no local anaesthetic was performed common on sternal BMAs and LPs. Local anaesthetics is an invasive procedure, and many of our physicians $(n=9)$ reported that it was insufficient for paediatric patients with AL and the procedure for local anaesthesia added more suffering to the patients. Instead, physical restraint was much more frequently used, as mentioned by 20 interviewees $(n=11$ paediatrician; $n=9$ parents); some of the studied parents $(n=5)$ were even involved with the restraining of their child-patient for treatment.

We barely use local anesthesia because that procedure itself is painful. The local anesthetic is injected intradermally to create a 'dome-size' to allow the medicine to infiltrate into the subcutaneous tissue. This procedure induced additional suffering to the children because of the additional shot. Parents often ask us to use local anesthesia before the procedure, but for LP, we use a 5 cc injection device that contains anesthetic. If the first puncture fails to reach the subarachoid space then lidocaine will be given by the device slowly while withdrawing the needle before another attempt is made by a spinal needle. However, if spinal fluid is aspirated, the child only suffers for one shot. (Paediatrician 9)

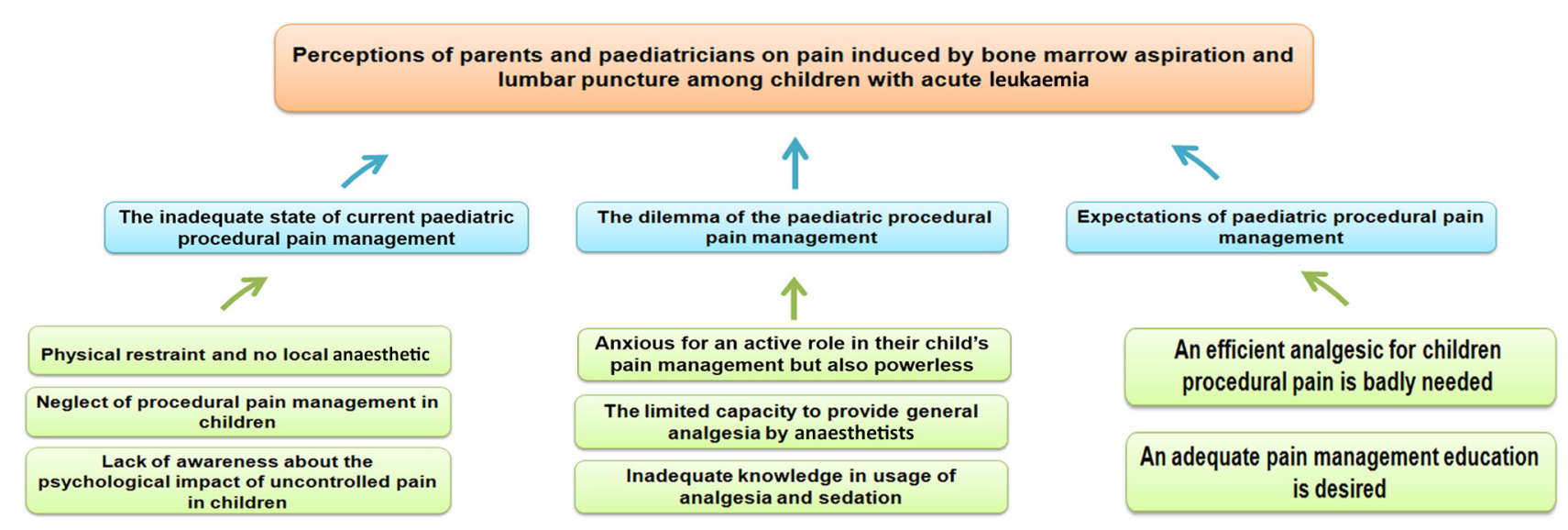

Figure 1 Key findings from parents and paediatricians perspectives. 
There is no analgesic used in sternal bone marrow aspiration. The subcutaneous tissue over the sternum is thin and only $1 \mathrm{~mL}$ of bone marrow is needed; we puncture once to minimize the additional suffering from an extra shot for local analgesic. (Paediatrician 3)

Poor thing, he struggled terribly (with physical restraint from several staff pressing him), howling and screaming, the bed was contaminated by his vomit. His whole face was smeared with nasal discharge, furthermore, several times, just after breakfast, all the food was vomited out. And the pants were soaked by the urine. The situation is so miserable (shakes her head). (Parent 7)

\section{Neglect of procedural pain management in children}

For many paediatricians $(n=9)$, they gave priority to the AL treatment but not the pain management for the repeated invasive diagnostic-therapeutic procedures. Most parents $(n=8)$ considered procedural pain as inevitable.

You have to conduct the procedure (with the help of physical restraint). You can not quit the procedure just because of pain. The major issue for our doctors to consider is to control the disease. If you fail to inject the medicine into the subarachnoid space and the patient acquires brain metastasis, all your efforts are in vain. (Paediatrician 6)

I deem the procedural pain my child suffered as impossible to avoid, because physicians are for my child's good. Even though I see him suffering from pain, I have to endure and help to press for the fulfillment of the procedure. For me it's OK, though he complains to me after the procedure. (Parent 1)

Lack of awareness about the psychological impact of uncontrolled pain in children

Children sense considerable pain even during the smallest interventions especially when they feel afraid. The psychological impact of undermanaged pain among this age group can be extensive (eg, traumatisation). ${ }^{29}$ The majority of the interviewed participants $(n=7$ paediatricians; $n=10$ parents) lacked awareness of the psychological impact of uncontrolled pain in children, while some parents $(n=4)$ even considered that pain may be educationally useful for the growth of their children. Such ideas were coupled with their belief that paediatric procedural pain was inevitable. As regarding the potential psychological impact of inadequate pain treatment on the child, they said:

It (the psychological impact of uncontrolled pain on the child) never comes to my mind. (Paediatrician 8)

This (the psychological impact of uncontrolled pain on the child)..., I am really unable to answer you, I have no idea about it. (Parent 5)
The dilemma of the paediatric procedural pain management The reports from parents and paediatricians on experiences coping with paediatric procedural pain were highly similar. All of them described their desire to have appropriate paediatric procedural pain management and inability to ensure adequate sedation analgesia in all the paediatric subjects.

Anxious for an active role in their child's pain management but also powerless

One of the greatest burdens that parents face with children suffering from childhood AL is stressful treatment related to repeated LPs and BMAs. ${ }^{30}$ In our study, all parents, regardless of their educational level, expressed their child's procedural pain process using similar descriptions such as 'anxiety', 'craving', 'helpless', 'powerless' and 'worthlessness'.

I would much rather endure the suffering for the child. When my child was crying and screaming during the bone marrow aspiration inside the room, I felt the needle pierce through my heart and I was crying outside the room. I felt completely helpless and could not do anything except hold him to cry together and let him suffer through the pain. I know nothing about pain management. I could only let him cry and encourage him to be brave and to take it like a man. (Parent 5)

The limited capacity to provide general analgesia by anaesthetists General analgesia carried out by anaesthesiologists for paediatric painful intrusive procedures is safe and effective. ${ }^{13}$ Paediatricians and parents clearly indicated that the ideal management is to perform the procedure under general anaesthesia. However, the problem is the anaesthesiologist is too busy to lend a helping hand. The interviewees' responses demonstrated that anaesthetists were unavailable to provide necessary sedation services for paediatric medical diagnostic and therapeutic procedures.

We have done the LP under general analgesia before but it created more trouble. One time we had made an appointment with an anesthetist at 8:00am; for an unforeseen reason, he could not make it to the operating room till the afternoon. The child had to fast the night before and after the procedure completed. He was simply scared and had been crying since that morning. It seemed as if we had induced more suffering to the child. (Paediatrician 3)

It is very difficult to gain help from the anesthetist, you know, you have to wait for the anesthetist to finish the scheduled operation first. Especially when my kid is on dexamethasone therapy, you know, it is easier for him to be hungry. He was starving but the anesthetist could not come. I was anxious. I waited and waited in the corridor, but he didn't come till eleven o'clock. You have no choice. If my son was on lumbar 
puncture, he needed to fast for at least fourhours from liquids and sixhours from solids after the procedure. What is more, sometimes you waited and waited, but in the end, the anesthetist failed to come. You had to press the child in the coach and forced him to undergo the procedure. (Parent 3)

\section{Inadequate knowledge in usage of analgesia and sedation}

In general, children are at a greater risk for sedation-related adverse events than adults, especially children with underlying conditions, such as leukaemia and other oncological diseases. ${ }^{31}$ Insufficient knowledge about analgesia and sedation usage accompanied with no specific reference standards to be followed also hinders paediatric procedural pain management. Overall, paediatricians mentioned that there was no pain management education for healthcare providers and most of them $(n=10)$ had no idea about pain management. Paediatricians' knowledge about the use of analgesia and sedation were inadequate, and some parents $(n=5)$ obtained incorrect information about the effect of sedation/analgesia from paediatricians.

Ideally, we would like to do the LP while the child is asleep and immobile. We have tried to use sedation but it was very difficult to give the just right amount. It is ineffective if not enough is administered, but it could cause respiratory arrest if too much is given. (Paediatrician 5)

We asked physicians about the analgesic previously. He told us to use it as little as possible. That one (Midazolam) was used today for the first time. After the injection, my son stopped crying and started an episode of laughing blankly. It is scary... (Parent 4)

\section{Expectations of paediatric procedural pain management}

Though there were many factors contributing to the lack of pain management in the paediatric patients, both the paediatricians and parents still expressed their desire for optimal interventions to improve the quality of paediatric procedural pain management.

An efficient analgesic for children's procedural pain is badly needed

Both for many paediatricians $(n=10)$ and parents $(n=12)$, an efficient analgesic for children procedural pain is badly needed, and safety should be its primary concern.

Although it (the pain he suffers) is inevitable, I think there must be certain measures to reduce the pain, the less pain suffered the better. (Parent 4)

Although we are busy, lack of time is not an excuse for not providing adequate pain relief in pediatric lumbar puncture and bone marrow aspiration. Bone marrow aspiration and lumbar puncture are relatively easy to perform but we need to have a safe, effective, and non-invasive analgesic pain control measure in clinical practice. (Paediatrician 6)
An adequate pain management education is desired

Paediatricians $(\mathrm{n}=9)$ also considered that improvement in physician's knowledge regarding pain management needed to be highlighted.

I hope there is adequate pain management education in all levels of physician training. Lack of knowledge and awareness in pain management leads to poor clinical practice. As far as I know, there is an optional pain management course offered in the university for training physicians. But the hospital management needs to provide similar courses to those who are currently practicing. I took a continuing education course on lumbar puncture years ago in Beijing, and local anesthesia was not even available at that time. (Paediatrician 8)

\section{DISCUSSION}

In this qualitative study, we described the current clinical practice of procedural pain management in our paediatric haemato-oncology department and found that suffering was not adequately recognised or properly treated.

LPs and BMAs are essential procedures to the paediatric haemato-oncology population. To help them control these medical procedures, it is important to explore how LPs and BMAs procedural pain is preserved in such contexts. Attitudes and experiences influencing medical procedural pain management have been studied from both the residents' and the care providers' perspective. The findings of the present study are consistent, to some degree, with the findings of other global research.

A previous study compared the practices of paediatric residents and emergency medicine residents and showed that paediatricians were using injectable local anaesthesia less often for LPs in children accompanied with the concern that injected lidocaine is painful, despite evidence that suggests otherwise. ${ }^{32}$ In the current hospital, the standardised practice for paediatric AL patients, LPs and BMAs procedural pain management is lidocaine infiltration at the puncture site. However, routine pain management practices were not consistent with the standard, and anaesthetic medication was barely used. Paediatricians regarded the puncture of lidocaine infiltration as an attempt when performed LPs in all children and used no medication of any kind in sternal BMAs. The painful intrinsic property of lidocaine infiltration was one of the major factors that discouraged them from using injectable local anaesthesia. Although the original intention to minimise the number of shots was admirable, children suffered more emotional distress while physical restraint was commonly used to successfully carry out these therapeutic or diagnostic procedures. In general, children's reactions were reported to be negative for physical restraint, including the following: anger, anxiety, abandonment, being punished in addition to fear, loss of control and vulnerability. ${ }^{33}$ The use of restraint could be justified as acting in the child's best interest, ${ }^{34}$ and the 
British Medical Association stated that it should only be used as a last resort. ${ }^{35}$

The analysis also revealed that at this paediatric department, a paediatric haemato-oncology care centre in a tertiary hospital in northwest China, paediatric procedural pain management had not been given enough attention among all operators. They focused on the 'treatment' and achieving 'recovery', while invasive procedures represented a necessary step in the treatment protocol. We also found that there is no relationship between the participating paediatricians' awareness of the LPs and BMAs procedural pain management, their years of clinical experience and their professional title. However, this is obviously contrary to the studies conducted by Kim $e t$ $a l^{36}$ and Nasser et $a l,{ }^{37}$ which found that the degree of attitude and knowledge status of pain management were correlated with physicians' personal experience. A possible explanation is: no clinical training in pain management and the deficiency of paediatric staff. According to the China Health Statistics Yearbook 2016, the total number of paediatricians in China has dropped from 105000 to 100000 in the past 5 years, with only 0.43 paediatricians per 1000 children. ${ }^{38}$ When the patient-to-paediatrician ratio is high, paediatricians, irrespective of academic titles, are consumed with busy clinical operations that interfere with stratified description of the phenomena. Paediatricians, especially for those with longer workinghistory, have been repeatedly experiencing children's anxiety and fear for longer periods, are just more inclined to express their perceptions sometimes.

In hospital, pain measurement is considered to be the fifth vital sign and therefore should be assessed and documented regularly with the other vital signs to assess the need and efficacy of analgesia given. ${ }^{39}$ Poorly managed pain in children has long been associated with a variety of short-term and long-term negative consequences. ${ }^{40}$ Pain in children, particularly if recurrent or repeated, can increase sensitivity to pain, fear and avoidance of healthcare in adulthood. ${ }^{41}$ However, in our study, neither paediatricians nor parents took the psychological impact of uncontrolled pain in children into consideration.

Attitudes and beliefs of paediatricians about pain management have been shown to influence assessment and treatment of children's pain. ${ }^{42}$ Thus, it is essential that healthcare workers realise their responsibilities and obligations for children's pain management. In our study, all of the paediatricians reported that there was no clinical training on pain management and nine $(82 \%)$ suggested that formal training would be useful. Of the residents who suggested training, three $(33 \%)$ directors mentioned that leaders of the hospital should be one of the trained subjects. Only when the leaders attach great importance to paediatric pain management would they organise the appropriate training and seminars, set up a procedural pain service group, develop clinical guidelines and make a far-sighted organisational policy (increasing the paediatrician/patient ratio). Given these results, we advocate for a formalised procedural training of pain management in paediatric residents and leaders, regarding the nature of pain, assessment skills and practical and theoretical knowledge about pain management.

Several investigations have revealed that having a child with leukaemia is an overwhelming life experience for both parents. Crisis reactions, such as shock, disbelief, despair, sorrow and anger, were described. ${ }^{43} 44$ Although these parents are confronted with various stressors that can elicit distress, medical procedural pain experience in children is among the most influential stressors. ${ }^{45}$ Despite the parents' own feelings, they have a key role in supporting their child through these needle-related medical procedures and determining the pain intensity their child is experiencing. ${ }^{46} 47$ In our study, parents' knowledge deficits related to lacking awareness about the damage of uncontrolled pain and low supportive ability in their children's pain management were identified. Findings from this study also indicate that parents have striven to alleviate the suffering of their child and enable support. They encouraged the child before he or she entered the operating room and waited outside. However, it should be noted that in this research centre, the principle of child medical operations is based on parents' absence. Power et $a l$, Salmela $e t$ al and Karlsson et al have showed that when children have to undergo an invasive medical procedure, it is important for children to have their parents present to help them to counteract their worries and fears. ${ }^{48-50}$ Their active involvement can give support to their children and can enhance their feelings of usefulness. ${ }^{51}$ According to these findings from the present study, we advocate that parents should be given appropriate opportunities to be present, appropriate information concerning their child's procedural pain and the use of non-pharmacological interventions for their children's pain relief.

An effective pain medication is urgently needed in China. When a procedure is expected to give children moderate pain and distress, local anaesthetics are insufficient as the only drugs in pain management. ${ }^{52}$ Sedation in children is often administered to control behaviour to allow the safe completion of a procedure, and it is different from that for adults. ${ }^{53}$ Often, children, especially those younger than 6 years, require deep levels of sedation to gain control of their behaviour. ${ }^{54}$ The WHO and the American Academy of Paediatrics recommended the combination of analgesic and sedative or general anaesthesia for paediatric procedural pain management in oncology. ${ }^{3}$ However, both of the methods can lead to serious or even life-threatening complications, such as hypoventilation, laryngospasm, airway obstruction, apnoea and cardiopulmonary impairment. ${ }^{29} \mathrm{High}$ security standards shall be maintained while performing a BMA in general anaesthesia or a deep sedation for a LP. ${ }^{55}$ We believe that the implementation of these cost-intensive procedures can only be ensured by establishing laws that require many disciplines involved in managing children's procedural pain (eg, anaesthesiology department or intensive care unit) or guidelines for non-anaesthetist doctors applying these services. ${ }^{5657}$ 
The ideal paediatric procedural pain management agent should be characterised by rapid onset, have a duration of action that is sufficient to get pain relief and have rapid recovery with minimal adverse effects. ${ }^{58}$ Expectations from our paediatricians are identical to this. To the authors' best knowledge, subanaesthetic concentrations of $\mathrm{N}_{2} \mathrm{O}$ produce only analgesic and anxiolytic effects without unconsciousness. ${ }^{59} \mathrm{~A}$ fixed nitrous oxide/ oxygen mixture can provide safe and effective analgesia for paediatric medical procedures. ${ }^{60-63}$ Additionally, the equipment needed for its administration is relatively inexpensive, minimal training is required for operators and no additional resuscitation equipment or staff is needed. Thus, there is a need for the introduction of this inhalational analgesic and sedative agent in Chinese scientific literature to conserve medical resources.

Furthermore, bone marrow collection for minimal residual disease (MRD) diagnosis should be replaced with peripheral blood collection in some cases. Minimising the number of medically unnecessary procedures is another strategy to minimise procedural pain. MRD diagnosis at the current research centre requires an average of 12times BMAs for each treatment course: the day of diagnosis, two different time points during the early phases of treatment for risk group assignment and subsequent time points after completion of induction therapy for treatment evaluation and intensity adjustment. ${ }^{64}$ It has been demonstrated that patients with B-lineage ALL, MRD is usually present at higher levels in bone marrow than in peripheral blood. This is not the case in T-lineage ALL where MRD levels in peripheral blood are similar to those in bone marrow. ${ }^{65}$ Based on these observations, blood instead of marrow was used to monitor MRD after completion of induction therapy in patients with T-lineage ALL (bone marrow is used for B-lineage ALL patients.) at St. Jude Children's Research Hospital. ${ }^{64}$ This raises the concern about improving the physicians' and students' medical English.

A further limitation of this study is that we conducted it in only one autonomous region. The result may not reflect the whole situation of China's paediatric patients' BMAs and LPs procedural pain management. However, the descriptions did reveal the current situation of paediatric patients' BMAs and LPs procedural pain control in this remote region of China.

\section{CONCLUSION}

This qualitative research suggests what characterises the state of paediatric BMAs and LPs procedural pain management in a remote part of China and calls for a pain management education programme for paediatricians and parents as well as an effective pain medication. It is the hope and expectation that our findings, the insights of paediatricians and parents will deepen our understanding of the barriers the clinic confronts and stimulate the establishment of strategies for children's pain management in China. The study findings cannot be generalised to the entire population as it was just conducted in a single setting.

Author affiliations

${ }^{1}$ Nursing School, Ningxia Medical University, Yinchuan, China

${ }^{2}$ Department of Paediatric Hematology-Oncology, General Hospital of Ningxia Medical University, Yinchuan, China

${ }^{3}$ Shanghai Mental Health Center, Shanghai Jiao Tong University School of Medicine, Shanghai, China

${ }^{4}$ Neurological Surgery Department, Ningxia People's Hospital, Yinchuan, China ${ }^{5}$ Department of Pharmacology, College of Pharmacy, Ningxia Medical University, Yinchuan, China

Acknowledgements The authors would like to thank all participants who generously shared their time and experiences. We thank Dr Guang-bo Bian (medical officer-in-charge of the paediatric haemato-oncology unit) for his help in participants' management. We also thank Hui-min Jin and Qun Huang (both of them are English teachers) for providing language help and writing assistance.

Contributors YW, QL, HX W, JN Y, LL G, YL D, XJ, GX M, XM C, YX L and JQ Y contributed to study conception, design, data collection and analyses; YW wrote the first draft of the manuscript; FZ, CF B, JL, YJ Z and YX L helped revise the draft manuscript; all authors reviewed and agreed on the submitted version of the manuscript. YX $L$ and JQ Y are guarantors for the study.

Funding The study was supported by Ningxia Plan for Science and Technology Support Foundation (grant no. 2015KJHM39). JN Y has had financial support from Science and Technology Department of Ningxia for the submitted work.

Competing interests None declared.

Patient consent Guardian consent obtained.

Ethics approval General Hospital of Ningxia Medical University Ethics Service Committee.

Provenance and peer review Not commissioned; externally peer reviewed.

Data sharing statement Full transcripts of the interviews and quotes and authorisation of the study are available by email from the corresponding author.

Open Access This is an Open Access article distributed in accordance with the Creative Commons Attribution Non Commercial (CC BY-NC 4.0) license, which permits others to distribute, remix, adapt, build upon this work non-commercially, and license their derivative works on different terms, provided the original work is properly cited and the use is non-commercial. See: http://creativecommons.org/ licenses/by-nc/4.0/

(c) Article author(s) (or their employer(s) unless otherwise stated in the text of the article) 2017. All rights reserved. No commercial use is permitted unless otherwise expressly granted.

\section{REFERENCES}

1. Ward E, DeSantis C, Robbins A, et al. Childhood and adolescent cancer statistics, 2014. CA Cancer J Clin 2014;64:83-103.

2. Zheng $\mathrm{R}$, Peng $\mathrm{X}$, Zeng $\mathrm{H}$, et al. Incidence, mortality and survival of childhood cancer in China during 2000-2010 period: A populationbased study. Cancer Lett 2015;363:176-80.

3. Zernikow B, Meyerhoff U, Michel E, et al. Pain in pediatric oncologychildren's and parents' perspectives. Eur J Pain 2005;9:395-406.

4. Kazak AE, Barakat LP. Brief report: parenting stress and quality of life during treatment for childhood leukemia predicts child and parent adjustment after treatment ends. J Pediatr Psychol 1997;22:749-58.

5. Stevens BJ, Yamada J, Estabrooks CA, et al. Pain in hospitalized children: Effect of a multidimensional knowledge translation strategy on pain process and clinical outcomes. Pain 2014;155:60-8.

6. Bartocci M, Bergqvist LL, Lagercrantz $\mathrm{H}$, et al. Pain activates cortical areas in the preterm newborn brain. Pain 2006;122:109-17.

7. Finley GA, Franck LS, Grunau RE, et al. Why Children's Pain Matters. Pain: Clinical Updates 2005;13:1-6.

8. Maurizi P, Russo I, Rizzo D, et al. Safe lumbar puncture under analgo-sedation in children with acute lymphoblastic leukemia. Int $J$ Clin Oncol 2014;19:173-7.

9. Chordas C. Post-dural puncture headache and other complications after lumbar puncture. J Pediatr Oncol Nurs 2001;18:244-59.

10. Marec-Bérard $\mathrm{P}$, Bissery $\mathrm{A}$, Kebaïli $\mathrm{K}$, et al. A positioning pillow to improve lumbar puncture success rate in paediatric haematology- 
oncology patients: a randomized controlled trial. BMC Cancer 2009;9:21.

11. Holdsworth MT, Raisch DW, Winter SS, et al. Differences among raters evaluating the success of EMLA cream in alleviating procedure-related pain in children with cancer. Pharmacotherapy 1997;17:1017-22.

12. Holdsworth MT, Raisch DW, Winter SS, et al. Pain and distress from bone marrow aspirations and lumbar punctures. Ann Pharmacother 2003;37:17-22.

13. Iannalfi A, Bernini G, Caprilli S, et al. Painful procedures in children with cancer: comparison of moderate sedation and general anesthesia for lumbar puncture and bone marrow aspiration. Pediatr Blood Cancer 2005;45:933-8.

14. Anghelescu DL, Burgoyne LL, Faughnan LG, et al. Prospective randomized crossover evaluation of three anesthetic regimens for painful procedures in children with cancer. $J$ Pediatr 2013;162:137-41.

15. Hjortholm N, Jaddini E, Hałaburda K, et al. Strategies of pain reduction during the bone marrow biopsy. Ann Hematol 2013;92:145-9.

16. Ellis JA, Villeneuve K, Newhook K, et al. Pain management practices for lumbar punctures: are we consistent? J Pediatr Nurs 2007;22:479-87.

17. Liossi C, White P, Hatira P. Randomized clinical trial of local anesthetic versus a combination of local anesthetic with selfhypnosis in the management of pediatric procedure-related pain. Health Psychol 2006;25:307-15.

18. Ireland AoPAoGBa. Good practice in postoperative and procedural pain management, 2nd edition. Paediatr Anaesth 2012;22(Suppl 1):1-79.

19. Ellis JA, McCarthy P, Hershon L, et al. Pain practices: a crossCanada survey of pediatric oncology centers. J Pediatr Oncol Nurs 2003:20:26-35.

20. Reed A, Thomas J, Roelofse J, et al. Guidelines for the safe use of procedural sedation and analgesia for diagnostic and therapeutic procedures in children: 2010. S Afr J Anaesthesiol Analg 2010;16(Suppl 1):S1-37

21. Sandelowski M. Whatever happened to qualitative description? Res Nurs Health 2000;23:334-40.

22. Merriam SB. Qualitative research: a guide to design and implementation. San Francisco: Jossey-Bass, 2009.

23. Li YX, Yu JQ, Tang L, et al. Cancer pain management at home: voice from an underdeveloped region of China. Cancer Nurs 2013;36:326-34.

24. Remmers $\mathrm{H}$, Holtgräwe $\mathrm{M}$, Pinkert $\mathrm{C}$. Stress and nursing care needs of women with breast cancer during primary treatment: a qualitative study. Eur J Oncol Nurs 2010;14:11-16.

25. Colaizzi PF. Psychological research as the phenomenologist views it. In: Valle RS, King M, eds. Oxford University Press. New York: Existential Phenomenological Alternatives for Psychology, 1978.

26. Braun V, Clarke V. Using thematic analysis in psychology. Qual Res Psychol 2006;3:77-101.

27. Thomas SP, Pollio HR. Listening to patients: a phenomenological approach to nursing research and practice: Springer, 2002.

28. Fusch PI, Ness LR. Are We There Yet? Data Saturation in Qualitative Research. The Qualitative Report 2015;20:1408-16.

29. Neuhäuser C, Wagner B, Heckmann M, et al. Analgesia and sedation for painful interventions in children and adolescents. Dtsch Arztebl Int 2010;107:241-7.

30. Caes L, Vervoort T, Devos P, et al. Parental distress and catastrophic thoughts about child pain: implications for parental protective behavior in the context of child leukemia-related medical procedures. Clin J Pain 2014;30:787-99.

31. Patel MM, Kamat PP, McCracken CE, et al. Complications of Deep Sedation for Individual Procedures (Lumbar Puncture Alone) Versus Combined Procedures (Lumbar Puncture and Bone Marrow Aspirate) in Pediatric Oncology Patients. Hosp Pediatr 2016;6:95-102.

32. Breakey VR, Pirie J, Goldman RD. Pediatric and emergency medicine residents' attitudes and practices for analgesia and sedation during lumbar puncture in pediatric patients. Pediatrics 2007;119:e631-6.

33. Demir A. The use of physical restraints on children: practices and attitudes of paediatric nurses in Turkey. Int Nurs Rev 2007;54:367-74.

34. Hull K, Clarke D. Restraining children for clinical procedures: a review of the issues issues that continue to challenge children's nursing. $\mathrm{Br}$ J Nurs 2010;19:346-50.

35. British Medical Association. Consent, Rights and Choices in health care for children and young people. BMJ Books 2001.

36. Kim MH, Park H, Park EC, et al. Attitude and knowledge of physicians about cancer pain management: young doctors of South Korea in their early career. Jpn J Clin Oncol 2011;41:783-91.

37. Nasser SC, Nassif JG, Saad AH. Physicians' Attitudes to Clinical Pain Management and Education: Survey from a Middle Eastern Country. Pain Res Manag 2016;2016:1-9.

38. National Health and Family Planning Commission. China health statistics Yearbook 2016. China Xie-he Medical University Publishing House 2016.

39. Lynch M. Pain as the fifth vital sign. J Intraven Nurs 2001;24:85-94.

40. Lee GY, Yamada J, Kyololo O, et al. Pediatric clinical practice guidelines for acute procedural pain: a systematic review. Pediatrics 2014;133:500-15.

41. Mc Grath PA. Psychological aspects of pain perception. In: Schechter NL, Berde CB, Yaster M, eds. Pain in infants, children and adolescents. Philadelphia: Lippincott, Williams and Wilkins, 1993:39-64.

42. Po' C, Benini F, Sainati L, et al. The opinion of clinical staff regarding painfulness of procedures in pediatric hematology-oncology: an Italian survey. Ital J Pediatr 2011;37:27.

43. Kars MC, Duijnstee MS, Pool A, et al. Being there: parenting the child with acute lymphoblastic leukaemia. J Clin Nurs 2008;17:1553-62.

44. Wills BS. Coping with a child with acute lymphocytic leukemia: the experiences of Chinese fathers in Hong Kong. Cancer Nurs 2009;32:E8-14.

45. Caes L, Vervoort T, Devos P, et al. Parental distress and catastrophic thoughts about child pain: implications for parental protective behavior in the context of child leukemia-related medical procedures. Clin J Pain 2014;30:787-99.

46. Ljungman G, Kreuger A, Gordh T, et al. Pain in pediatric oncology: do the experiences of children and parents differ from those of nurses and physicians? Ups J Med Sci 2006;111:87-96.

47. Karlsson K, Englund AC, Enskär K, et al. Parents' perspectives on supporting children during needle-related medical procedures. Int J Qual Stud Health Well-being 2014;9:23759.

48. Power N, Liossi C, Franck L. Helping parents to help their child with procedural and everyday pain: practical, evidence-based advice. J Spec Pediatr Nurs 2007;12:203-9.

49. Salmela M, Aronen ET, Salanterä S. The experience of hospitalrelated fears of 4- to 6-year-old children. Child Care Health Dev 2011;37:719-26.

50. Karlsson K, Dalheim Englund AC, Enskär K, et al. Experiencing Support During Needle-Related Medical Procedures: A Hermeneutic Study With Young Children (3-7Years). J Pediatr Nurs 2016;31:667-77.

51. He HG, Pölkki T, Pietilä AM, et al. A survey of Chinese nurses' guidance to parents in children's postoperative pain relief. J Clin Nurs 2005;14:1075-82.

52. Vantaa Benjaminsson M, Thunberg G, Nilsson S. Using Picture and Text Schedules to Inform Children: Effects on Distress and Pain during Needle-Related Procedures in Nitrous Oxide Sedation. Pain Res Treat 2015;2015:1-6.

53. Coté CJ, Wilson S. Guidelines for Monitoring and Management of Pediatric Patients Before, During, and After Sedation for Diagnostic and Therapeutic Procedures: Update 2016. Pediatr Dent 2016;38:13-39.

54. Coté CJ, Wilson S. American Academy of PediatricsAmerican Academy of Pediatric DentistryWork Group on Sedation. Guidelines for monitoring and management of pediatric patients during and after sedation for diagnostic and therapeutic procedures: an update. Pediatrics 2006;118:2587-602.

55. Krauss B, Green SM. Procedural sedation and analgesia in children. Lancet 2006;367:766-80.

56. Knape JT, Adriaensen $\mathrm{H}$, van Aken $\mathrm{H}$, et al. Guidelines for sedation and/or analgesia by non-anaesthesiology doctors. Eur J Anaesthesiol 2007;24:563-7.

57. Havidich JE, Cravero JP. The current status of procedural sedation for pediatric patients in out-of-operating room locations. Curr Opin Anaesthesiol 2012;25:453-60.

58. Slavik VC, Zed PJ. Combination ketamine and propofol for procedural sedation and analgesia. Pharmacotherapy 2007;27:1588-98.

59. Emmanouil DE, Quock RM. Advances in understanding the actions of nitrous oxide. Anesth Prog 2007;54:9-18.

60. Annequin D, Carbajal R, Chauvin P, et al. Fixed $50 \%$ nitrous oxide oxygen mixture for painful procedures: a French survey. Pediatrics 2000;105:E47.

61. Gudgin EJ, Besser MW, Craig Jl. Entonox as a sedative for bone marrow aspiration and biopsy. Int J Lab Hematol 2008;30:65-7.

62. Pedersen RS, Bayat A, Steen NP, et al. Nitrous oxide provides safe and effective analgesia for minor paediatric procedures-a systematic review. Dan Med J 2013;60:A4627. 
63. Babl FE, Belousoff J, Deasy C, et al. Paediatric procedural sedation based on nitrous oxide and ketamine: sedation registry data from Australia. Emerg Med J 2010;27:607-12.

64. Campana D. Progress of minimal residual disease studies in childhood acute leukemia. Curr Hematol Malig Rep 2010;5:169-76.
65. Campana D. Role of minimal residual disease monitoring in adult and pediatric acute lymphoblastic leukemia. Hematol Oncol Clin North Am 2009;23:1083-98. 